\title{
Morphea: Clinical Considerations and Management
}

\section{(1) Muazzez Çiğdem Oba, (1) Özge Așkın, (1) Burhan Engin}

Istanbul University-Cerrahpasa, Cerrahpasa Faculty of Medicine, Department of Dermatology and Venereology, Istanbul, Turkey

\section{ABSTRACT}

Morphea, also known as localized scleroderma, is a sclerosing disease of unknown etiology that involves mainly dermal and subcutaneous layers of skin. Several types of morphea exist and various clinical manifestations are encountered. Early clinical diagnosis is crucial to minimize functional and cosmetic sequelae. Treatment choice depends on activity, extent of disease and depth of involvement. In this review, we aimed to review clinical features and current treatment options for morphea.

Keywords: Localized scleroderma, Morphea, Treatment

\section{Introduction}

Morphea, also known as localized scleroderma, is a sclerosing skin disease that mainly affects dermal and subcutaneous layers of the skin without internal organ involvement. Histologically, there is increased collagen deposition in dermis. Depending on subtype, adjacent sites such as muscles, bones and joints can be affected. Morphea can severely impact quality of life by causing cosmetic and sometimes functional problems. Early diagnosis and treatment is crucial to minimize potential sequelae.

\section{Clinical features}

Depending upon the severity, extent and depth of involvement, five main clinical variants of morphea are described: limited, generalized, linear, deep, and mixed (Table 1) [1].

Plaque type morphea is the most common presentation of morphea [1,2,3]. Initially, oval or round erythematous indurated plaques are seen, mostly on the trunk. Central sclerosis develops with time, which is surrounded by an active liliac halo. Hyperpigmented plaques that show central depression are features of late lesions (Figure 1). Guttate morphea and atrophoderma of Pasini and Pierini are variants of limited morphea characterized by truncal sclerotic lesions measuring less than $1 \mathrm{~cm}$ in diameter [1,2].

Generalized forms include generalized morphea and disabling pansclerotic morphea. Generalized morphea is diagnosed when four or more plaques, measuring larger than $3 \mathrm{~cm}$ involve two or more anatomical sites (Figure 2) [4]. Pansclerotic morphea is a very rare variant presenting with extensive full-thickness skin involvement sparing acral skin. It is more commonly observed in children compared to adults [4]. Some authors also consider eosinophilic fasciitis (Shulman's syndrome) to be part of generalized forms of morphea [1]. Pseudo-cellulitis appearance

\section{Table 1. Classification of morphea}

\begin{tabular}{|l|l|}
\hline Limited morphea & $\begin{array}{l}\text { - Plaque morphea } \\
\text { - Guttate morphea } \\
\text { - Atrophoderma of Pasini and Pierini }\end{array}$ \\
\hline Generalized morphea & $\begin{array}{l}\text { - Generalized morphea } \\
\text { - Disabling pansclerotic morphea }\end{array}$ \\
\hline Linear & $\begin{array}{l}\text { - Linear morphea of the extremities } \\
\text { - Linear morphea of the face ("en coup de } \\
\text { sabre" and Parry Romberg syndrome) }\end{array}$ \\
\hline Deep & - \\
\hline Mixed & - \\
\hline
\end{tabular}


of proximal extremities and blood eosinophilia are features of eosinophilic fasciitis.

Linear form of morphea presents with longitudinal streaks of sclerosis. It may be located on upper or lower extremities sometimes causing flexion contractures and limb length discrepancies (Figure 3). Other typical location of linear morphea is scalp or the face, also known as "en coup de sabre" variant. Paramedian depression on the forehead and scarring alopecia of the scalp are the most common clinical features (Figure 4). Parry Romberg syndrome is the severe subtype of "en coup de sabre" lineer morphea. There is loss of subcutaneous fat in entire hemifacial region resulting in facial asymmetry. Ocular and neurologic abnormalities may accompany linear morphea of the face $[1,4]$.

Deep form of morphea affects deeper tissues such as subcutaneous fat, fascia and muscle. Mixed type is the combination of more than one morphea subtypes, combined linear and plaque type being the most common [1,2].

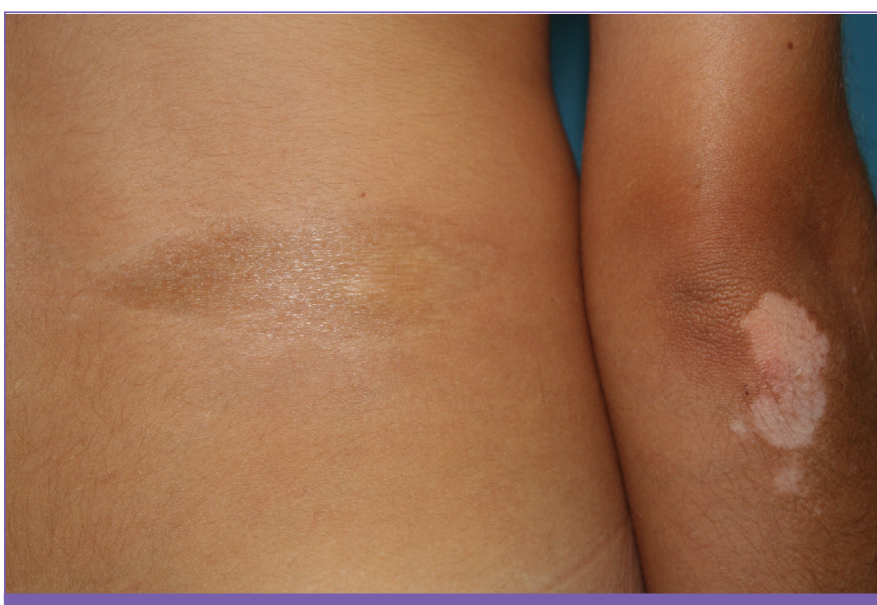

Figure 1. Hyperpigmented sclerotic plaque morphea is seen on lumbar region along with vitiligo patch on the elbow

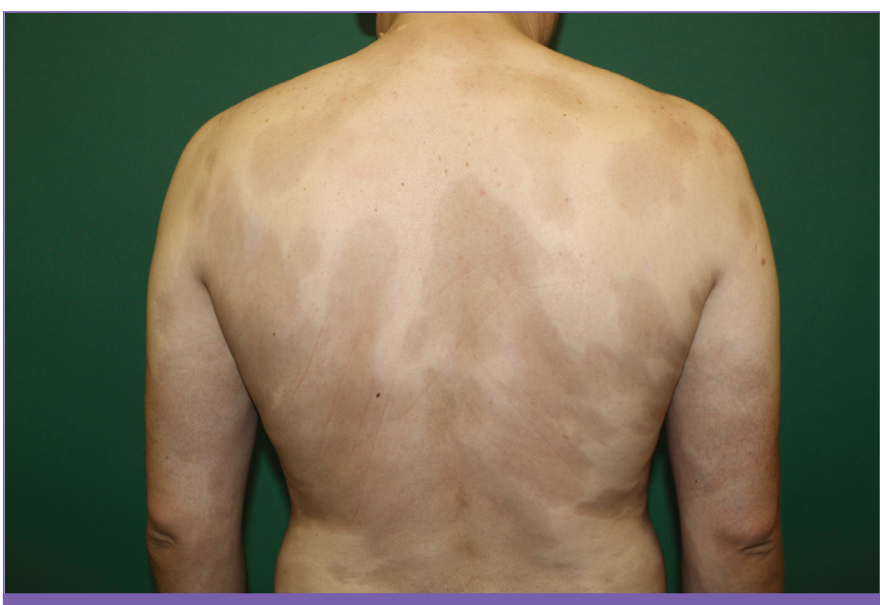

Figure 2. Generalized morphea
Extracutaneous involvement may be seen in morphea. In a multinational study involving seven hundred fifty juvenile patients with morphea, up to one forth of the children had extracutaneous manifestations, articular, neurologic, vascular and ocular findings being more common [5]. Arthritis is the most common extracutanous finding, seen especially in linear and generalized morphea. Arthritis frequently affects the joints underlying morphea plaques, however distant involvement may also occur [6]. In some cases,

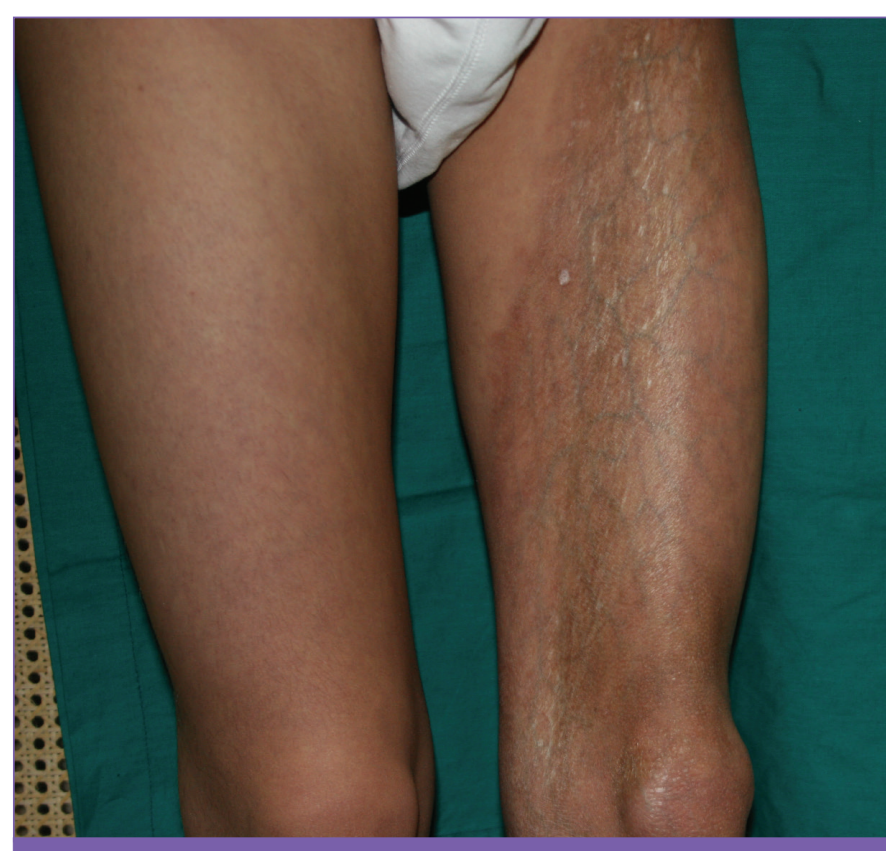

Figure 3. Linear morphea of the extremities

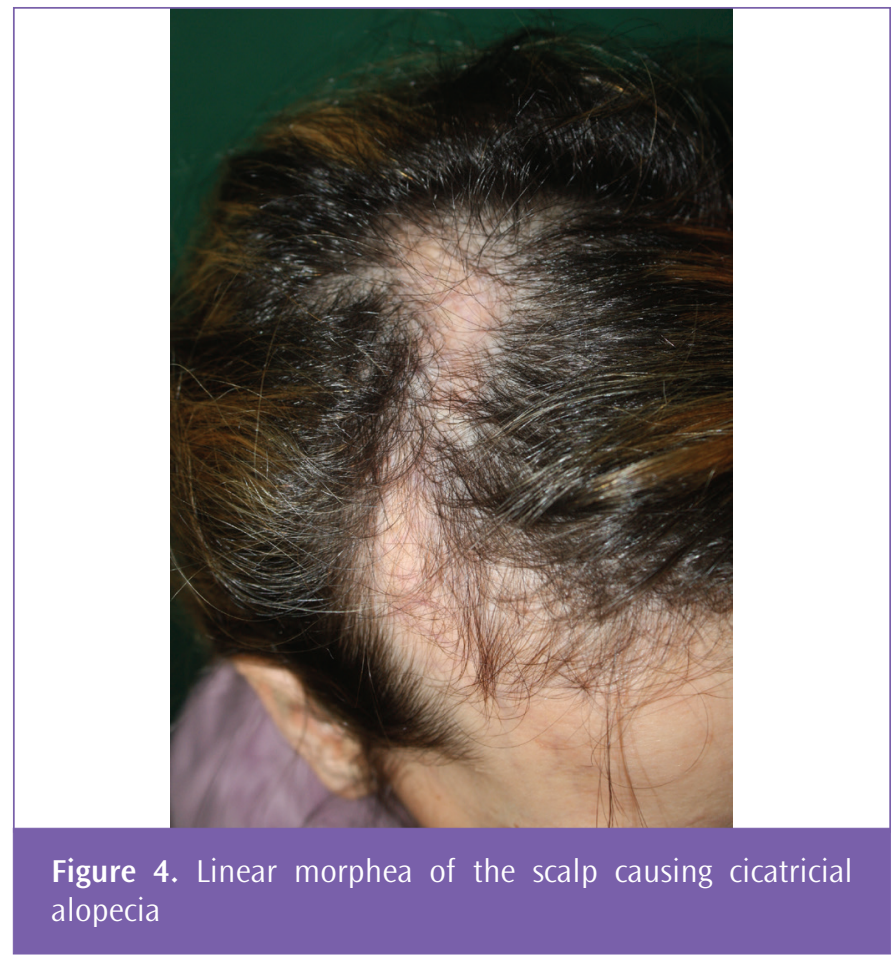


arthritis may lead to limb length discrepancies and limited range of motion [5]. Patients with linear scleroderma of the face have the most considerable risk for neurologic involvement, including seizures and headache. Vascular involvement was reported as deep vein thrombosis and Raynaud's phenomenon. Ocular involvement consisting of uveitis, episcleritis, acquired glaucoma, xerophthalmia and keratitis were exclusively seen in patients with linear scleroderma of the face [5]. Patients with linear scleroderma of the face should be monitored with periodic eye examinations [5].

\section{Laboratory changes}

Unlike systemic sclerosis, there are no reliable laboratory markers for the diagnosis of morphea. Increased sedimentation rate and eosinophilia can occur in active disease and during relapses [7]. In patients with deep involvement leading to myositis, serum creatine kinase and aldolase levels may increase [2]. Prevalence of antinuclear antibodies and rheumatoid factor (RF) is higher in patients with extracutaneous involvement [5]. RF is considered as a significant marker for articular involvement [5]. However, routine screening for these autoantibodies is not recommended. Likewise, routine blood screening for Borrelia burgdorferi is not recommended [2].

\section{Imaging}

Patients with severe linear scleroderma of the face, especially the Parry Romberg variant may have associated neurologic disturbances. Some authors include magnetic resonance imaging (MRI) among standard diagnostic procedures of such patients [8]. MRI can also help confirm musculoskeletal manifestations such as joint effusion, synovitis, bone marrow involvement etc [9].

\section{Differential diagnosis}

Lipodermatosclerosis, especially the acute form may be misdiagnosed as morphea. Lipodermatosclerosis typically involves the lower extremities and there is accompanying findings of venous hypertension [10].

Lipoatrophy following intraarticular steroid injections may be misdiagnosed as morphea [11]. The lack of erythema, dyspigmentation and induration in a linear plaque points to lipoatrophy rather than morphea.

Radiation induced fibrosis (RIF) usually develops in the first 3 months after radiotherapy and may mimic morphea. RIF has insidious onset and there is no erythema and induration. Of note, localized morphea following radiotherapy has been reported in literature with an incidence of 2 out of 1,000 patients [12].

Early lesions of linear morphea of the face show erythema without sclerosis and thus may be misdiagnosed as a vascular malformation including an acquired port-wine stain [13,14].
Carcinoma en cuirasse is a rare form of cutaneous metastasis that occurs mostly due to breast cancer. In patients with sclerotic plaques involving the chest wall, malignancy should be ruled out by skin biopsy if the patient has any risk factors for breast cancer [15].

Cutaneous T cell lymphomas, especially early stage mycosis fungoides, may resemble morphea. Immunohistochemistry is a helpful adjunct to differentiate the two entities [16].

Generalized morphea and pansclerotic morphea should be differentiated from scleroderma, which is a complex connective tissue disease with multi-system involvement. Clinical findings are essential to distinguish the two entities histopathologic examination of the skin shows similar findings. Raynaud phenomenon, acrosclerosis and sclerodactyly are typically absent in morphea and nail capillaroscopy is normal [6,17]. Anti-centromere antibodies and anti-Scl-70 antibodies are also absent in sera of patients with morphea [18].

\section{Treatment}

There is a wide range of therapeutic options available for the treatment of morphea. The choice of treatment modality depends on the depth and extent of involvement and the clinical activity of the disease [2].

Topical steroids are the most commonly preferred first line treatment for cases of morphea with limited involvement [19]. Despite the lack of randomized controlled studies, active disease without deep inflammation is first treated by a 3-month course of moderate- to high-potent topical corticosteroids. Occlusion may be applied in selected patients for better results. Intralesional steroid injections are also appropriate to halt lesion progression in localized active disease $[2,6]$.

Topical tacrolimus $0.1 \%$ ointment with or without occlusion can be considered for treatment of active plaque morphea [20,21,22]. In a small double-blind placebo controlled study 10 patients were treated with tacrolimus $0.1 \%$ ointment and petrolatum for 12 weeks. Significant improvement was seen in active plaque morphea lesions treated with tacrolimus [22].

Topical calcipotriol $0.005 \%$ was shown to effectively improve morphea lesions previously not responsive to topical steroids. The ointment was applied twice daily under occlusion. Weekly calcipotriol dose should not exceed $50 \mathrm{~g} / \mathrm{m}^{2}[23,24]$.

Topical imiquimod 5\% has also been proposed as an alternative therapeutic option for the treatment of plaque morphea. The mechanism of action of imiquimod is thought to involve the induction of T helper1 cytokine response [25]. However, currently, topical imiquimod cannot be recommended for morphea as there is limited data [2]. 
Efficacy of fractional carbon dioxide laser was assessed for the treatment of localized morphea. Compared with local low-dose ultraviolet A1 (UVA1) phototherapy, fractional carbon dioxide laser led to better improvement of lesional skin clinically, histopathologically and by ultrasound [26].

Phototherapy is the first-line treatment option for extensive or rapidly progressing disease without deep involvement and can also be considered for patients with limited involvement that are unresponsive to topical treatment [6]. The long wavelength of UVA radiation affects the culprit fibroblasts and inflammatory cells at the level of deep dermis [27]. Ultraviolet light also induce the matrix metalloproteinases and promote neovascularization [28]. Different from topical treatments, phototherapy not only improves existing lesions but it also prevents formation of new ones [6]. Among various modalities, UVA1 phototherapy has the highest level of evidence. It can be administered at low (10-29 J/(cm²), medium $\left(30-59 \mathrm{~J} / \mathrm{cm}^{2}\right)$ and high $\left(60-130 \mathrm{~J} / \mathrm{cm}^{2}\right)$ dose, all of which might be effective to improve sclerosis [2,6]. Most patients receive low to medium dose UVA1 for a total of 20 to 40 sessions [27]. Eighteen out of 20 patients with severe morphea had at least $80 \%$ clearance of their lesions when treated with low dose UVA1 $\left(20 \mathrm{~J} / \mathrm{cm}^{2}\right)$ for 30 sessions [29]. Medium dose UVA1 is also effective in treatment of morphea with better long-term results compared with low-dose UVA1 [30,31,32]. Broadband UVA, PUVA phototherapy (oral, bath and cream) and narrowband UVB can be considered as alternatives when UVA1 phototherapy is not available [27].

Morphea lesions with deep involvement or lesions causing functional impairments should be treated with systemic therapies [6]. Methotrexate (MTX) has the most evidence for efficacy, proven by randomized controlled studies. For the first 2 to 3 months of MTX therapy, systemic corticosteroids may be added to treatment in case of rapidly progressing disease or functional impairment. In a placebo controlled study involving 70 pediatric patients with morphea, rates of clinical efficacy was significantly higher and the likelihood of relapse was significantly lower with MTX (15 to $20 \mathrm{mg}$ weekly) treatment as compared to placebo [33]. Of note both groups were treated with systemic corticosteroids for the first 3 months of therapy. In management of juvenile morphea, "Childhood Arthritis and Rheumatology Research Alliance" workgroup compared effectiveness of three different treatment regimens in a 1-year observational cohort study: MTX alone, or in combination with intravenous (30 mg/kg/dose for 3 months) or oral corticosteroids ( $2 \mathrm{mg} / \mathrm{kg} /$ day). Their results showed that are all three regiments are effective in more than $75 \%$ of patients [34].

In case of intolerance to or ineffectiveness with MTX, mycophenolate mofetil may be used as a safe alternative treatment option [35].
Two cases of children with pansclerotic morhea and five pediatric patients with refractory morphea were treated with intravenous tocilizumab, an anti-interleukin-6 receptor antibody [36,37]. All patients improved without any adverse events, however further studies are needed to confirm effectiveness and safety of tocilizumab therapy for morphea.

Autologous fat grafting is currently considered as ideal treatment for inactive linear morphea of the face [38]. Soft tissue fillers such as hyaluronic acid may also be used in selected patients where there is less tethering to underlying tissues [39].

\section{Ethics}

Peer-review: Internally peer-reviewed.

\section{Authorship Contributions}

Concept: M.Ç.O., Ö.A., B.E., Design: M.Ç.O., Ö.A., B.E., Data Collection or Processing: Ö.A., B.E., Literature Search: M.Ç.O., Ö.A., B.E., Writing: M.Ç.O., Ö.A., B.E.

Conflict of Interest: No conflict of interest was declared by the authors.

Financial Disclosure: The authors declared that this study received no financial support.

\section{References}

1. Kreuter A, Krieg T, Worm M, Wenzel J, Moinzadeh P, Kuhn A, Aberer E, Scharffetter-Kochanek K, Horneff G, Reil E, Weberschock T, Hunzelmann N. German guidelines for the diagnosis and therapy of localized scleroderma. J Dtsch Dermatol Ges 2016;14:199-216.

2. Knobler R, Moinzadeh P, Hunzelmann N, Kreuter A, Cozzio A, Mouthon L, Cutolo M, Rongioletti F, Denton CP, Rudnicka L, Frasin LA, Smith V, Gabrielli A, E Aberer E, Bagot M, Bali G, Bouaziz J, Braae Olesen A, Foeldvari I, Frances C, Jalili A, Just U, Kähäri V, Kárpáti S, Kofoed K, Krasowska D, Olszewska M, Orteu C, Panelius J, Parodi A, Petit A, Quaglino P, Ranki A, Sanchez Schmidt JM, Seneschal J, Skrok A, Sticherling M, Sunderkötter C, Taieb A, Tanew A, Wolf P, Worm M, Wutte NJ, Krieg T. European Dermatology Forum S1-guideline on the diagnosis and treatment of sclerosing diseases of the skin, Part 1: localized scleroderma, systemic sclerosis and overlap syndromes. J Eur Acad Dermatology Venereol 2017;31:1401-1424.

3. Bulur I, Erdoan HK, Karapnar T, Saracoglu ZN. Morphea in Middle Anatolia, Turkey: A 5-year single-center experience. Postep Dermatologii i Alergol 2017;34:334-338.

4. Laxer RM, Zulian F. Localized scleroderma. Curr Opin Rheumatol 2006;18:606613.

5. Zulian F, Vallongo C, Woo P, Russo R, Ruperto N, Harper J, Espada G, Corona F, Mukamel M, Vesely R, Musiej-Nowakowska E, Chaitow J, Ros J, Apaz MT, Gerloni V, Mazur-Zielinska H, Nielsen S, Ullman S, Horneff G, Wouters C, Martini G, Cimaz R, Laxer R, Athreya BH; Juvenile Scleroderma Working Group of the Pediatric Rheumatology European Society (PRES). Localized scleroderma in childhood is not just a skin disease. Arthritis Rheum 2005;52:2873-2881.

6. Florez-Pollack S, Kunzler E, Jacobe HT. Morphea: Current concepts. Clin Dermatol 2018;36:475-486.

7. Marzano A V., Menni S, Parodi A, Borghi A, Fuligni A, Fabbri P, Caputo R. Localized scleroderma in adults and children. Clinical and laboratory investigations of 239 cases. Eur J Dermatol 2003;13:171-176. 
8. Sommer A, Gambichler T, Bacharach-Buhles M, von Rothenburg T, Altmeyer P, Kreuter A. Clinical and serological characteristics of progressive facial hemiatrophy: a case series of 12 patients. J Am Acad Dermatol 2006;54:227233.

9. Agata K, Kawashima H, Kumada A, Kashiwagi Y, Hara H. Clinical usefulness of magnetic resonance imaging in four children with scleroderma. Arch Rheumatol 2018;33:230-235.

10. Miteva M, Romanelli P, Kirsner RS. Lipodermatosclerosis. Dermatol Ther 2010;23:375-388.

11. Call JE, Mann JA, Linos KD, Perry A, Yost J. Linear lipoatrophy following intra - articular triamcinolone acetonide injection mimicking linear scleroderma. Pediatr Dermatol 2019;36:e56-e57.

12. Alhathlool A, Hein R, Andres C, Ring J, Eberlein B. Post-irradiation morphea: Case report and review of the literature. J Dermatol Case Rep 2012;6:73-77.

13. Pickert AJ, Carpentieri D, Price H, Hansen RC. Early morphea mimicking acquired port-wine stain. Pediatr Dermatol 2014;31:591-594.

14. Ng SS-Y, Tay Y-K. Inflammatory morphea mimicking an acquired port-wine stain initially treated with pulsed-dye laser. J Cosmet Laser Ther 2015;17:277280 .

15. Culver AL, Metter DM, Pippen JE. Carcinoma en cuirasse. Proc (Bayl Univ Med Cent) 2019;32:263-265.

16. Basir HRG, Alirezaei P, Rezanejad A, Daneshyar S. Early morphea simulating patch-stage mycosis fungoides in two cases. Dermatol Reports 2018;10:7471.

17. Morgan ND, Hummers LK. Scleroderma Mimickers. Curr Treatm Opt Rheumatol 2016;2:69-84.

18. Krieg T, Takehara K. Skin disease: a cardinal feature of systemic sclerosis. Rheumatology (Oxford) 2009;48 Suppl 3:iii14-8.

19. Strickland N, Patel G, Strickland A, Jacobe H. Attitudes and trends in the treatment of morphea: A national survey. J Am Acad Dermatol 2015;72:727728.

20. Mancuso G, Berdondini RM. Localized scleroderma: response to occlusive treatment with tacrolimus ointment. Br J Dermatol 2005;152:180-182.

21. Stefanaki C, Stefanaki K, Kontochristopoulos G, Antoniou C, Stratigos A, Nicolaidou E, Gregoriou S, Katsambas A. Topical tacrolimus $0.1 \%$ ointment in the treatment of localized scleroderma. An open label clinical and histological study. J Dermatol 2008;35:712-718.

22. Kroft EB, Groeneveld TJ, Seyger MM, de Jong EM. Efficacy of Topical Tacrolimus 0.1\% in Active Plaque Morphea. Am J Clin Dermatol 2009;10:181-187.

23. Cunningham BB, Landells IDR, Langman C, Sailer DE, Paller AS. Topical calcipotriene for morphea/linear scleroderma. I Am Acad Dermatol 1998;39:211-215.

24. Tay YK. Topical calcipotriol ointment in the treatment of morphea. J Dermatolog Treat 2003;14:219-221.

25. Dytoc M, Wat H, Cheung-Lee M, Sawyer D, Ackerman T, Fiorillo L. Evaluation of the efficacy and safety of topical imiquimod $5 \%$ for plaque-type Morphea: A multicenter, prospective, vehicle-controlled trial. J Cutan Med Surg 2015;19:132-139.
26. Shalaby SM, Bosseila M, Fawzy MM, Abdel Halim DM, Sayed SS, Allam RS. Fractional carbon dioxide laser versus low-dose UVA-1 phototherapy for treatment of localized scleroderma: a clinical and immunohistochemical randomized controlled study. Lasers Med Sci 2016;31:1707-1715.

27. Teske NM, Jacobe HT. Phototherapy for sclerosing skin conditions. Clin Dermatol 2016;34:614-622.

28. York NR, Jacobe HT. UVA1 phototherapy: A review of mechanism and therapeutic application. Int J Dermatol 2010;49:623-630.

29. Kerscher M, Volkenandt M, Gruss C, Reuther T, von Kobyletzki G, Freitag M, Dirschka T, Altmeyer P. Low-dose UVA1 phototherapy for treatment of localized scleroderma. J Am Acad Dermatol 1998;38:21-26.

30. Camacho NR, Sánchez JE, Martin RF, González JR, Sánchez JL. Medium-dose UVA1 phototherapy in localized scleroderma and its effect in CD34-positive dendritic cells. J Am Acad Dermatol 2001;45:697-699.

31. de Rie MA, Enomoto DN, de Vries HJ, Bos JD. Evaluation of medium-dose UVA1 phototherapy in localized scleroderma with the cutometer and fast Fourier transform method. Dermatology 2003;207:298-301.

32. Sator PG, Radakovic S, Schulmeister K, Hönigsmann H, Tanew A. Mediumdose is more effective than low-dose ultraviolet A1 phototherapy for localized scleroderma as shown by 20-MHz ultrasound assessment. J Am Acad Dermatol 2009;60:786-791.

33. Zulian F, Martini G, Vallongo C, Vittadello F, Falcini F, Patrizi A, Alessio M, La Torre F, Podda RA, Gerloni V, Cutrone M, Belloni-Fortina A, Paradisi $\mathrm{M}$, Martino S, Perilongo $\mathrm{G}$. Methotrexate treatment in juvenile localized scleroderma: a randomized, double-blind, placebo-controlled trial. Arthritis Rheum 2011;63:1998-2006.

34. Li SC, Torok KS, Rabinovich CE, Dedeoglu F, Becker ML, Ferguson PJ, Hong SD, Ibarra MF, Stewart K, Pope E, Higgins GC, Laxer RM, Mason T, Fuhlbrigge RC, Andrews T; CARRA Registry Investigators. Initial Results from a Pilot Comparative Effectiveness Study of Three Methotrexate-Based Consensus Treatment Plans for Juvenile Localized Scleroderma. J Rheumatol 2019. pii: jrheum.190311.

35. Mertens JS, Marsman D, van de Kerkhof PC, Hoppenreijs EP, Knaapen HK, Radstake TR, de Jong EM, Seyger MM. Use of mycophenolate mofetil in patients with severe localized scleroderma resistant or intolerant to methotrexate. Acta Derm Venereol 2016;96:510-513.

36. Martini G, Campus S, Raffeiner B, Boscarol G, Meneghel A, Zulian F. Tocilizumab in two children with pansclerotic morphoea: A hopeful therapy for refractory cases? Clin Exp Rheumatol 2017;35 Suppl 106:211-213.

37. Lythgoe H, Baildam E, Beresford MW, Cleary G, McCann LJ, Pain CE. Tocilizumab as a potential therapeutic option for children with severe, refractory juvenile localized scleroderma. Rheumatology (Oxford) 2018;57:398-401.

38. Barin EZ, Cinal H, Cakmak MA, Tan O. Treatment of Linear Scleroderma (en Coup de Sabre) With Dermal Fat Grafting. J Cutan Med Surg 2016;20:269-271.

39. Thareja SK, Sadhwani D, Alan Fenske N. En coup de sabre morphea treated with hyaluronic acid filler. Report of a case and review of the literature. Int J Dermatol 2015;54:823-826. 